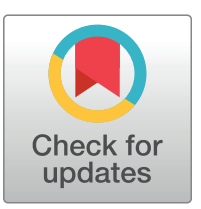

G open ACCESS

Citation: Moskowitz NA, Roland AB, Fischer EK, Ranaivorazo N, Vidoudez C, Aguilar MT, et al. (2018) Seasonal changes in diet and chemical defense in the Climbing Mantella frog (Mantella laevigata). PLoS ONE 13(12): e0207940. https:// doi.org/10.1371/journal.pone.0207940

Editor: Alex V. Chaves, The University of Sydney, AUSTRALIA

Received: July 11, 2018

Accepted: November 8, 2018

Published: December 26, 2018

Copyright: @ 2018 Moskowitz et al. This is an open access article distributed under the terms of the Creative Commons Attribution License, which permits unrestricted use, distribution, and reproduction in any medium, provided the original author and source are credited.

Data Availability Statement: All data is either included in the supplementary materials or have been deposited on Data Dryad (doi: 10.5061/dryad. s7f2gk3).

Funding: This work was supported by Harvard University Bauer Fellowship (http://archive.sysbio harvard.edu/CSB/research/fellows.html) to LA0; National Science Foundation (www.nsf.gov) IOS1557684 to LAO; National Geographic Society (www.nationalgeographic.org/grants) 9685-15 to LAO; Howard Hughes Medical Institute Professor's
RESEARCH ARTICLE

\section{Seasonal changes in diet and chemical defense in the Climbing Mantella frog (Mantella laevigata)}

Nora A. Moskowitz ${ }^{1}$, Alexandre B. Roland $\mathbb{D}^{2}$, Eva K. Fischer ${ }^{1}$, Ndimbintsoa Ranaivorazo ${ }^{3}$, Charles Vidoudez ${ }^{4}$, Marianne T. Aguilar ${ }^{5}$, Sophia M. Caldera ${ }^{5}$, Jacqueline Chea ${ }^{5}$, Miruna G. Cristus ${ }^{5}$, Jett P. Crowdis ${ }^{5}$, Bluyé DeMessie ${ }^{5}$, Caroline R. desJardins-Park ${ }^{5}$, Audrey H. Effenberger ${ }^{5}$, Felipe Flores ${ }^{5}$, Michael Giles ${ }^{5}$, Emma Y. He ${ }^{5}$, Nike S. Izmaylov ${ }^{5}$, ChangWon C. Lee ${ }^{5}$, Nicholas A. Pagel ${ }^{5}$, Krystal K. Phu ${ }^{5}$, Leah U. Rosen ${ }^{5}$, Danielle A. Seda ${ }^{5}$, Yong Shen ${ }^{5}$, Santiago Vargas ${ }^{5}$, Andrew W. Murray ${ }^{2,5}$, Eden Abebe ${ }^{6}$, Sunia A. Trauger ${ }^{4}$, David A. Donoso ${ }^{7}{ }^{7}$, Miguel Vences ${ }^{8}$, Lauren A. O'Connell ${ }^{1,5 *}$

1 Department of Biology, Stanford University, Stanford, California, United States of America, 2 Center for Systems Biology, Harvard University, Cambridge, Massachusetts, United States of America, 3 Department of Biology, Faculty of Science, University of Antananarivo, Antananarivo, Madagascar, 4 FAS Small Molecule Mass Spectrometry Facility, Harvard University, Cambridge, Massachusetts, United States of America, 5 LS50: Integrated Science Freshman Class, Harvard University, Cambridge, Massachusetts, United States of America, 6 Cambridge Rindge and Latin High School, Cambridge, Massachusetts, United States of America, 7 Departamento de Biología, Escuela Politécnica Nacional, Quito, Ecuador, 8 Braunschweig University of Technology, Zoological Institute, Braunschweig, Germany

*loconnel@stanford.edu

\section{Abstract}

Poison frogs acquire chemical defenses from the environment for protection against potential predators. These defensive chemicals are lipophilic alkaloids that are sequestered by poison frogs from dietary arthropods and stored in skin glands. Despite decades of research focusing on identifying poison frog alkaloids, we know relatively little about how environmental variation and subsequent arthropod availability impacts alkaloid loads in poison frogs. We investigated how seasonal environmental variation influences poison frog chemical profiles through changes in the diet of the Climbing Mantella (Mantella laevigata). We collected M. laevigata females on the Nosy Mangabe island reserve in Madagascar during the wet and dry seasons and tested the hypothesis that seasonal differences in rainfall is associated with changes in diet composition and skin alkaloid profiles of $M$. laevigata. The arthropod diet of each frog was characterized into five groups (i.e. ants, termites, mites, insect larvae, or 'other') using visual identification and cytochrome oxidase 1 DNA barcoding. We found that frog diet differed between the wet and dry seasons, where frogs had a more diverse diet in the wet season and consumed a higher percentage of ants in the dry season. To determine if seasonality was associated with variation in frog defensive chemical composition, we used gas chromatography / mass spectrometry to quantify alkaloids from individual skin samples. Although the assortment of identified alkaloids was similar across seasons, we detected significant differences in the abundance of certain alkaloids, which we hypothesize reflects seasonal variation in the diet of $M$. laevigata. We suggest that these variations could originate from seasonal changes in either arthropod leaf litter composition or changes in 
Award (www.hhmi.org/developing-scientists/hhmiprofessors) 520008146 to AWM. The funders had no role in study design, data collection and analysis, decision to publish, or preparation of the manuscript.

Competing interests: The authors have declared that no competing interests exist. frog behavioral patterns. Although additional studies are needed to understand the consequences of long-term environmental shifts, this work suggests that alkaloid profiles are relatively robust against short-term environmental perturbations.

\section{Introduction}

Many animals have evolved chemical defenses to deter predators and parasites [1,2]. Although small molecule chemical defenses are rare among vertebrates [3], some clades of amphibians have evolved alkaloid-based defenses, including Neotropical poison frogs (dendrobatids and bufonids) as well as the less studied clades of mantellid poison frogs from Madagascar, myobatrachids (Pseudophryne) frogs from Australia, and eleutherodactylid frogs from Cuba [4, 5]. Indeed, over 800 unique alkaloids have been identified from poisonous amphibians [6]. Dendrobatid and mantellid poison frogs do not produce alkaloids themselves, but rather sequester them from their diet of leaf litter arthropods [7]. Alkaloids are stored in specialized skin granular glands to be actively released in a stress response [5, 8]. Observations from captive breeding colonies of poison frogs led to the dietary hypothesis of poison frog chemical defense, as poison frogs raised in captivity lack alkaloids but can acquire them in alkaloid feeding experiments $[9,10]$. As diet and chemical profiles are tightly linked in poison frogs, there have been many studies attempting to link variation in diet to the striking chemical diversity seen within and among poison frog species [7, 11-15]. Despite progress in understanding these trophic relationships, little is known about how changes in environmental parameters influence the diet and skin chemical profiles of poison frogs.

Poison frog sequestration of defensive alkaloid chemicals from arthropods is a remarkable example of convergent evolution that requires innovations in amphibian physiology and behavior. While the best studied clade for chemical defenses are Neotropical dendrobatids [13, 16, 17], some mantellids of Madagascar (genus Mantella) also sequester alkaloid compounds from their arthropod diet [9]. Neotropical dendrobatids and Malagasy mantellids shared their last common ancestor nearly 150 million years ago [18] and each are more closely related to undefended clades than to each other. Yet extensive sampling of both lineages over several decades has revealed the presence of hundreds of similar alkaloids [5]. Examples include histrionicotoxins, pumiliotoxins, and decahydroquinolines that target voltage-gated sodium channels and nicotinic acetylcholine channels in the nervous system [19-21]. There is some evidence that alkaloid auto-resistance has also convergently evolved in dendrobatids and mantellids, where similar mutations in the voltage-gated sodium channel pore have been documented and hypothesized to confer alkaloid resistance in these two frog families [22]. In addition to physiological adaptations, both lineages have evolved behavioral adaptations to support chemical defenses [23]. Besides diurnal activity patterns, the acquired chemical defenses co-occur with a dietary specialization of ants and mites [13]. Initial reports in some dendrobatid frogs showed ants and mites made up 50-90\% of the diet while closely related non-toxic frogs had only $12-16 \%$ of their diet consisting of ants and mites [24, 25]. Several species of Mantella have a similar abundance of ants and mites in their diet as poisonous dendrobatid frogs $[11,26]$. The extent to which chemical defense is driven by an active preference for alkaloid-containing prey [27] and/or simply reflects differences in local arthropod abundance is currently unclear in both clades.

The diversity of arthropod communities in different habitats is hypothesized to explain much of the variation that is seen between different populations of the same poison frog 
species in both the dendrobatid and mantellid clades [15, 28, 29]. Along with geographic differences in arthropod community composition, seasonal changes in environmental variables also influence arthropod communities. For example, leaf litter moisture plays a large role in leaf litter arthropod distribution and abundance [30-33]. Arthropod species abundance and diversity also drastically change between the wet and dry tropical seasons [34] and across years [33]. Since poison frog chemical defense is tightly linked to dietary arthropods, fluctuations in arthropod community composition and abundance likely influence poison frog chemical profiles. Research on the Strawberry poison frog (Oophaga pumilio) in Panama has shown there are both geographic and seasonal fluctuations in chemical profiles [16], highlighting the fine spatial and temporal scales at which poison frog chemical defenses can vary. However, the diet contents of these frogs were not reported, and so how variation in alkaloid profiles links to variation in diet remains unexplored in the context of seasonal variation.

This study investigated the seasonal fluctuations of diet and alkaloid composition in the Climbing Mantella (Mantalla laevigata), a mantellid poison frog endemic to Madagascar (Fig 1). We tested the general hypothesis that both diet and alkaloid profiles would change between the wet and dry seasons. To test this hypothesis, we collected M. laevigata females on the island reserve of Nosy Mangabe off the northeastern coast of Madagascar in both the wet and dry seasons. We then analyzed stomach contents and quantified alkaloid profiles of frogs collected in both seasons. Notably, key components of arthropod diet characterization were completed by first-year university students during the ecology module of an experimental science course integrating mathematics, chemistry, biology, and computational approaches into a semesterlong lab. Our findings are the first to analyze both diet and alkaloid profiles in the context of seasonal variation in poison frogs and contribute to our understanding of how environmental change may impact poison frog diet and chemical defenses.

\section{Materials and methods}

\section{Field collections}

Adult female Climbing Mantella (Mantella laevigata) were captured on the island of Nosy Mangabe in November-December 2015 during the local dry season $(\mathrm{N}=11$, average mass \pm standard deviation: $1.79 \pm 0.25 \mathrm{~g}$ ) and July-September 2016 during the local rainy (wet) season $(\mathrm{N}=9$, average mass \pm standard deviation: $1.64 \pm 0.17 \mathrm{~g})$. Differences in rainfall during these periods reflect local variation in rainfall rather than the major seasons typically associated with Madagascar as a whole (S1 Fig). We collected only adult females for this study because brain tissues were shared with a related study exploring female behavior, allowing us to minimize the number of wild-caught animals collected. Briefly, reproductive females caring for tadpoles were collected in the wet season while non-reproductive females were collected in the dry season. Frogs were collected during the day with a plastic cup and stored individually in plastic bags with air and leaf litter for 25 to $30 \mathrm{~min}$. Individual frogs were photographed, anesthetized with a topical application of $20 \%$ benzocaine to the belly, and euthanized by cervical transection. The dorsal skin (from the back of the head but not including the legs) was isolated and stored in glass vials containing $1 \mathrm{ml}$ of $100 \%$ methanol. Stomachs were dissected and their contents were stored in $1 \mathrm{ml}$ of $100 \%$ ethanol. Remaining frog tissues were preserved in either RNAlater (Life Technologies, Carlsbad, CA, USA) or 100\% ethanol. Muscle and skeletal tissue were deposited in the amphibian collection of the Zoology and Animal Biodiversity Department of the University of Antananarivo, Madagascar. Two additional frog specimens were archived in the Museum of Comparative Zoology at Harvard University (Herpetology A150719-20). Collection permits (242/15/MEEMF/SG/DGF/DSAP/SCB and 140/16/MEEMF/ SG/DGF/DSAP/SCB) were issued by Direction générale des forêts et Direction des aires 


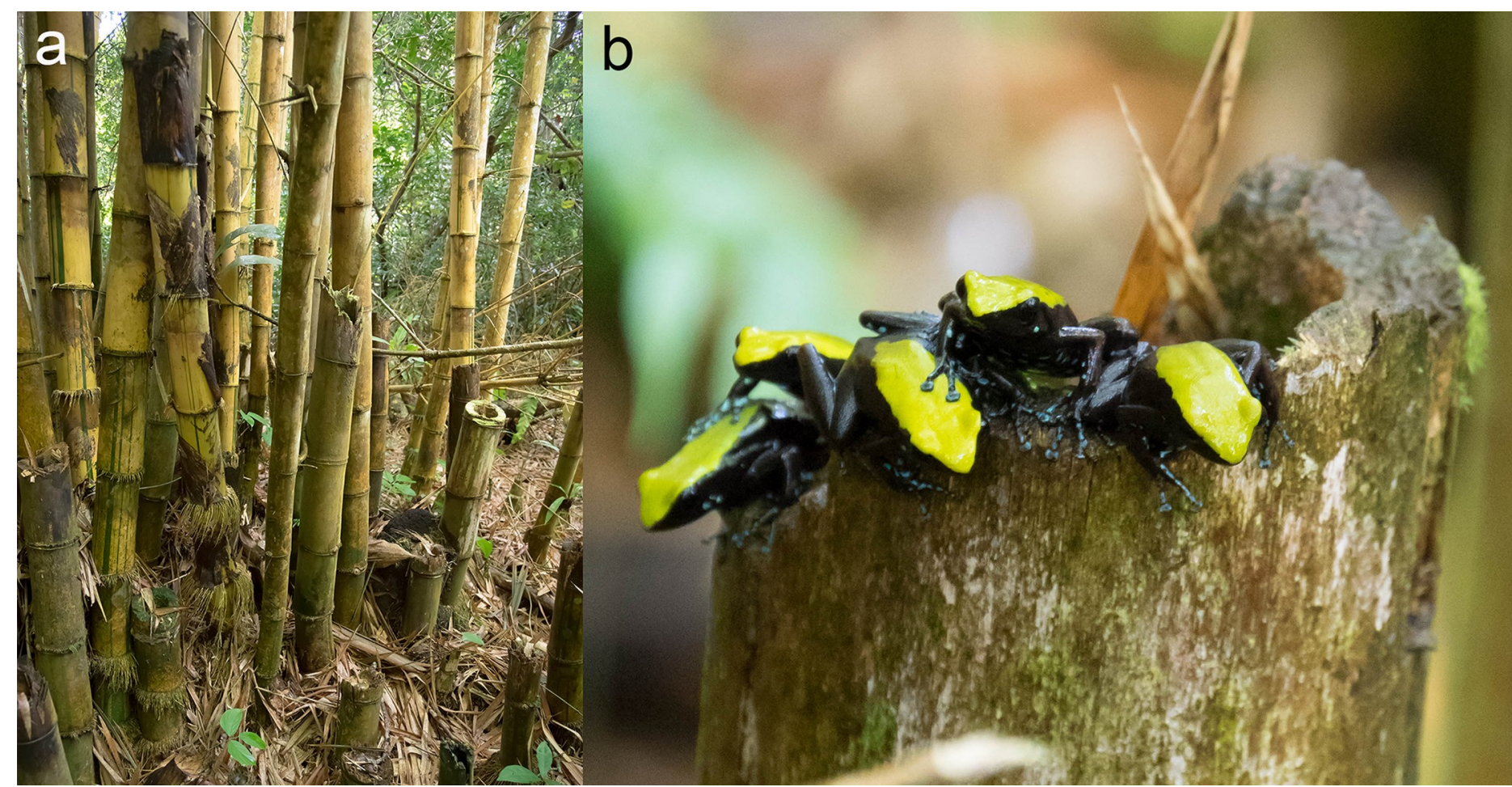

Fig 1. The Climbing Mantella (Mantella laevigata) in its habitat. (a) The Nosy Mangabe Reserve contains many areas with large bamboo. (b) These bamboo shoots are used by $M$. laevigata as breeding pools.

https://doi.org/10.1371/journal.pone.0207940.g001

protégées terrestres (Forestry Branch and Terrestrial Protected Areas Directorate of Madagascar). Exportation of specimens to the United States was completed under CITES permits (1051C-EA12/MG15 and 679C-EA08/MG16). The Institutional Animal Care and Use Committee of Harvard University approved all procedures (protocol 15-03-239).

\section{Diet analyses}

Arthropods in stomach contents. Arthropod sorting and identification via DNA barcoding was completed by university freshmen during the ecology lab of an integrative science course. Protocols were modified to fit within a three-hour laboratory course and we note all deviations from manufacturer's instructions below. Stomach contents were placed into a petri dish containing phosphate buffered saline (1X PBS). Individual prey items were sorted and assigned a unique seven-digit identification number with the first four digits being the frog voucher specimen number and the last three digits being the number assigned to the prey item based on the order in which it was isolated. Each arthropod was photographed with a Lumenera Infinity 2 camera mounted on an Olympus dissecting microscope (SZ40) and stored in $100 \%$ ethanol for one week. All prey item photos are available on DataDryad (doi: 10.5061/ dryad.s7f2gk3).

Diet was quantified by both percent number and percent volume of each arthropod prey type (ants, mites, termites, insect larvae, or "other") to account for variation in prey size. Adult arthropods that did not fall into discrete dietary categories (flies, beetles etc.) were placed in the "other" category, while all insect larvae were placed in "insect larvae" category. Volume was determined by taking length and width measurements from photographs imported into ImageJ (National Institute of Health, Bethesda, Maryland, USA). Length was measured from 
the foremost part of the prey item (including mandibles if applicable) and extended to the rearmost part of the prey item (excluding ovipositors if applicable). Width was measured at the midpoint and excluded appendages. Length and width measurements were then used to calculate the volume of each prey item using the equation for a prolate spheroid: $\mathrm{V}=(4 \pi / 3)^{*}$ $(\text { Length } / 2)^{*}(\text { Width } / 2)^{\wedge} 2$. For spherical mites, volume was calculated using the equation for a sphere: $\mathrm{V}=(4 \pi / 3)^{*}$ (Radius)^3.

Molecular identification of stomach contents. DNA from arthropods was isolated using the NucleoSpin Tissue kit (Macherey-Nagel, Bethlehem, PA, USA) according to manufacturer's instructions with a few deviations to make the protocol amenable to an undergraduate laboratory course. The arthropods were placed in T1 buffer (from the NucleoSpin Tissue kit), crushed with a pestle, and incubated in Proteinase $\mathrm{K}$ solution at $56^{\circ} \mathrm{C}$ overnight. Samples were then frozen at -20 ${ }^{\circ} \mathrm{C}$ for one week. Extraction of genomic DNA then proceeded according to manufacturer's instructions and purified genomic DNA was stored at $-20{ }^{\circ} \mathrm{C}$ for one week. We used PCR to amplify a segment of the cytochrome oxidase 1 (CO1 or coxl) gene from the mitochondrial DNA, the standard marker for DNA barcoding. $\mathrm{CO} 1$ was amplified using the general arthropod primers LCO-1490 (5' - GGTCAACAAATCATAAAGATATTGG) and HCO-2198 (5'-TAAAC TTCAGGGTGACCAAAAATCA) from Folmer et al. [35]. For all reactions, we used $2 \mu \mathrm{L}$ of each primer $(10 \mu \mathrm{M})$ and $25 \mu \mathrm{L}$ of $2 \mathrm{X}$ Phusion High-Fidelity PCR Master Mix with GC Buffer (New England Biolabs, Ipswich, MA, USA) in a total reaction volume of $50 \mu \mathrm{L}$. We used a touchdown PCR program to amplify CO1 as follows: $95^{\circ} \mathrm{C}$ for $5 \mathrm{~min} ; 5$ cycles of $95^{\circ} \mathrm{C}$ for $30 \mathrm{~s}, 45^{\circ} \mathrm{C}$ for $30 \mathrm{~s}$ with $-1^{\circ} \mathrm{C}$ per cycle, $72^{\circ} \mathrm{C}$ for $1 \mathrm{~min}$; and 40 rounds of $95^{\circ} \mathrm{C}$ for $30 \mathrm{~s}, 40^{\circ} \mathrm{C}$ for $30 \mathrm{~s}$, and $72^{\circ} \mathrm{C}$ for 1 min; ending with a single incubation of $72^{\circ} \mathrm{C}$ for $5 \mathrm{~min}$. PCR reactions were stored at $-20^{\circ} \mathrm{C}$ for one week and then run on a 1\% SyberSafe/agarose gel (Life Technologies). Successful reactions with a single band of the expected size were purified with the E.Z.N.A. Cycle Pure Kit (Omega Bio-Tek, Norcross, GA, USA). We successfully amplified and sequenced the target DNA segment from 103 out of 518 (19.9\%) of ant samples, 19 out of 82 (23.2\%) of mite samples, 1 out of 23 (4.3\%) of termite samples, 16 out of 18 (88.9\%) of larvae samples, and 27 out of 187 (14.4\%) "other" arthropods. Purified PCR products were Sanger sequenced by GeneWiz Inc. (Cambridge, MA, USA). Sequences are available on GenBank (MG947212-MG947379).

We used DNA barcode sequences to qualitatively identify the prey items recovered from stomach contents. Barcode sequences were imported into Geneious (v 11.0.3) for trimming and alignment of forward and reverse sequencing reactions. We used nucleotide BLAST from the NCBI Genbank nr database to identify all arthropods (S2 Table), and nucleotide BLAST from the BOLD Identification System (IDS, http://www.boldsystems.org/index.php/IDS_OpenIdEngine) to identify our CO1 ant sequences to the species level (S3 Table). This is because the BOLD database is more ant-focused than the Genbank nr database, which increases the likelihood of obtaining a correct match for ant $\mathrm{CO} 1$ barcode sequences. We assigned an order, family, genus or species level annotation based on results of the BOLD IDS or Genbank search. We considered results that yielded greater than $96 \%$ sequence similarity as sufficient to assign genera or species [36]. For less than 95\% BOLD IDS similarity, we assigned specimens to an order or family. For certain specimens, results of the IDS search were more taxonomically ambiguous than others. Some specimens only matched to order, rather than a specific family or genus. For the remaining ants without barcode sequences, photographs were used to identify each whole ant specimen to morphospecies using the barcoded ants as a reference.

\section{Chemical analyses}

Isolation of alkaloids. Alkaloids were extracted as previously described in McGugan et al. [15] and as briefly described below. We extracted alkaloids from individual frog samples, 
including nine frog skins from the wet season and eleven frog skins from the dry season. Prior to extraction, skin samples were weighed with an analytical scale. The skin and the entire contents of each sample vial (whole tissue piece and methanol) were emptied into a sterilized Dounce homogenizer. To ensure the transfer of all materials, the empty vial was rinsed with 1 $\mathrm{ml}$ of methanol and this methanol was also added to the homogenizer. Before homogenization, $25 \mu \mathrm{g}$ of D3-nicotine (Sigma-Aldrich, St Louis, MO, USA) in methanol was added to each homogenizer to serve as an internal standard. The skin sample was then ground with the piston ten times in the homogenizer before being transferred to a glass vial. The homogenizer was rinsed with an additional $1 \mathrm{ml}$ of methanol in order to collect all alkaloid residues, and this methanol was also added to the final glass vial. All equipment was cleaned with a triple rinse of methanol between samples. Samples were stored at $-20^{\circ} \mathrm{C}$ until further processing.

Gas Chromatography / Mass Spectrometry (GC/MS). One ml of each methanol skin extract was evaporated to dryness under nitrogen flow and resuspended in $100 \mu \mathrm{l}$ of methanol. Samples were analyzed on a Trace 1310 GC coupled with a Q-Exactive Hybrid quadrupoleorbitrap mass spectrometer (ThermoFisher Scientific, Waltham, MA USA). The GC was fitted with a Rxi-5Sil MS column ( $30 \mathrm{~m}, 0.25 \mathrm{~mm}$ ID, $0.25 \mu \mathrm{m}$ film, with a $10 \mathrm{~m}$ guard column, Restek, Bellefonte, PA, USA). One $\mu \mathrm{l}$ of sample was injected at split 25 in the inlet maintained at $280^{\circ} \mathrm{C}$. The GC program was as follows: $100^{\circ} \mathrm{C}$ for $2.5 \mathrm{~min}$, then to $280^{\circ} \mathrm{C}$ at $8^{\circ} \mathrm{C} \mathrm{min}^{-1}$ and held at that final temperature for $5 \mathrm{~min}$. Transfer lines to the MS were kept at $250^{\circ} \mathrm{C}$. The MS source was operated in electron ionization (EI) positive ion mode, at $300^{\circ} \mathrm{C}$. The MS acquired data at 60000 resolution, with an automatic gain control target of $1 \times 10^{6}$, automatic injection times and a scan range of 33 to $750 \mathrm{~m} / \mathrm{z}$. Mass spectrometry files are available on DataDryad (doi: 10.5061/dryad.s7f2gk3).

\section{Data analysis}

Except where noted, all analyses were conducted in R, v 3.4.2 using RStudio v1.1.383. All figures were generated using the R package 'ggplot2' v 2.21 and aesthetically edited using Adobe Illustrator $\mathrm{v}$ 16.0.0. The normality of both the diet and alkaloid datasets, separated by seasonal groups, were tested with the Shapiro-Wilk test for normality using the $\mathrm{R}$ 'stats' package v 3.4.2; the fixed effect was consumption and the random effect was the type of prey consumed. Neither set followed a normal distribution. To deal with these deviations from normality, we used a non-parametric Mann-Whitney $\mathrm{U}$ tests performed in the $\mathrm{R}$ 'stats' package $\mathrm{v}$ 3.4.2 to compare alkaloid quantities and relative volumes among diet categories between wet and dry season individuals.

Dietary arthropods. To compare stomach contents across M. laevigata populations, we quantified the relative number and volume of all specimens recovered from the stomach contents, including ants, mites, insect larvae, termites and other arthropods (S1 Table). Diet variables were not normally distributed and a non-parametric Mann-Whitney $U$ test was used to compare diet categories between wet and dry season individuals. Using the $\mathrm{R}$ 'vegan' package $\mathrm{v} 2.5-1$, we calculated a Bray-Curtis dissimilarity index for each diet category comparison and plotted the results in two dimensions using a non-metric multidimensional scaling (NMDS). Samples in the resulting NMDS plot were greyscale coded based on season to help visualize the wet and dry seasons frog samples. Polygons were calculated using the 'ordihull' function in $\mathrm{R}$ using the 'vegan' package v. 2.5-1. The purpose of 'ordihull' is to create neat, convex outlines to further delineate group separation for visual clarity. A single outline is generated to create a simple polygon that includes all points within an assigned group. We used NMDS twice: to examine the relationship between percent volume and percent number of consumed 
arthropods between season. We followed our NMDS analyses with permutational multivariate analysis of variance (PERMANOVA) on Bray-Curtis dissimilarities between the samples.

To gain more detailed understanding of what prey the frogs consumed, we performed separate analyses on the three most commonly consumed prey items of ants, arachnids, and other categories. For ants, we included in this analysis only whole ants identified to species or morphospecies level by either morphology or molecular barcodes (S3 Table). For arachnids and other categories, we used prey items that received a reliable $\mathrm{CO} 1$ barcode sequence match to the BLASTn database and were classified to order. These data, represented by the percent number of specific prey types eaten within each category (ants, arachnids, and "other"), were not normally distributed. As such, a non-parametric Mann-Whitney U test was used to compare diet categories between wet and dry season individuals.

Analysis of alkaloid data. Alkaloids were tentatively identified using the mass spectral data provided in Daly et al [6]. The mass to charge ratio, relative retention times, and relative intensity information was incorporated into a Mass Spectral Transfer File and imported into AMDIS (NIST [37]). This library was used to automatically identify peaks deconvoluted by AMDIS. The identification was weighted by the retention index (calculated from the retention time provided in Daly et al [6]), and the retention index of a few easily identifiable compounds like the D3-Nicotine internal standard. Intensities of the model ions for each candidate alkaloid were extracted from the AMDIS results files and normalized to the mass of skin used for each frog's alkaloid extraction.

We restricted our analysis to 41 alkaloids that were present in at least half of the individuals in the study and used this data set to conduct statistical analysis between seasonal groups ( $\mathrm{S} 4$ Table). The mass spectra of these 41 candidates of interest were manually inspected and compared to the Daly database, as well as to the mass spectra in the NIST14 database, to confirm alkaloid identification. To examine overall alkaloid presence between groups, we calculated a Bray-Curtis dissimilarity index for each alkaloid in the comparison and then plotted the results in two dimensions using a non-metric multidimensional scaling (NMDS). Samples in the resulting NMDS plot were greyscale coded based on season to help visualize how M. laevigata individuals differ between the wet and dry seasons in alkaloid composition. We followed our NMDS analyses with permutational multivariate analysis of variance (PERMANOVA) on Bray-Curtis dissimilarities between the samples. To test if the variance in each group was significantly different, we performed an analysis of similarity (ANOSIM) in the vegan R package v 2.5-1. We used a non-parametric Mann-Whitney U test to test for differences in alkaloid abundance in wet and dry season frogs. We then used permutation testing to control for multiple comparisons among the large number of alkaloids. Permuted datasets $(n=250)$ were generated by randomly re-assigning wet/dry season labels to individual samples. If the real $\mathrm{p}$-value for a given alkaloid fell in the extreme $5 \%$ of the distribution of permuted $p$-values for that alkaloid, we called that alkaloid differentially abundant between wet and dry season samples.

\section{Results}

\section{Seasonal differences in diet}

We quantified arthropod prey items isolated from $M$. laevigata stomach contents to determine if diet differed between dry and wet seasons (Fig 2). On average, dry season M. laevigata individuals consumed $44 \%$ more in absolute volume than wet season individuals (S1 Table). We visualized overall differences in diet characteristics using non-metric multidimensional scaling (NMDS) plots (Fig 2A and 2B). Main prey item classes differed between wet and dry seasons in both percent number $(\mathrm{U}=8, p=0.002)$ and percent volume $(\mathrm{U}=6, p=0.001)$. 

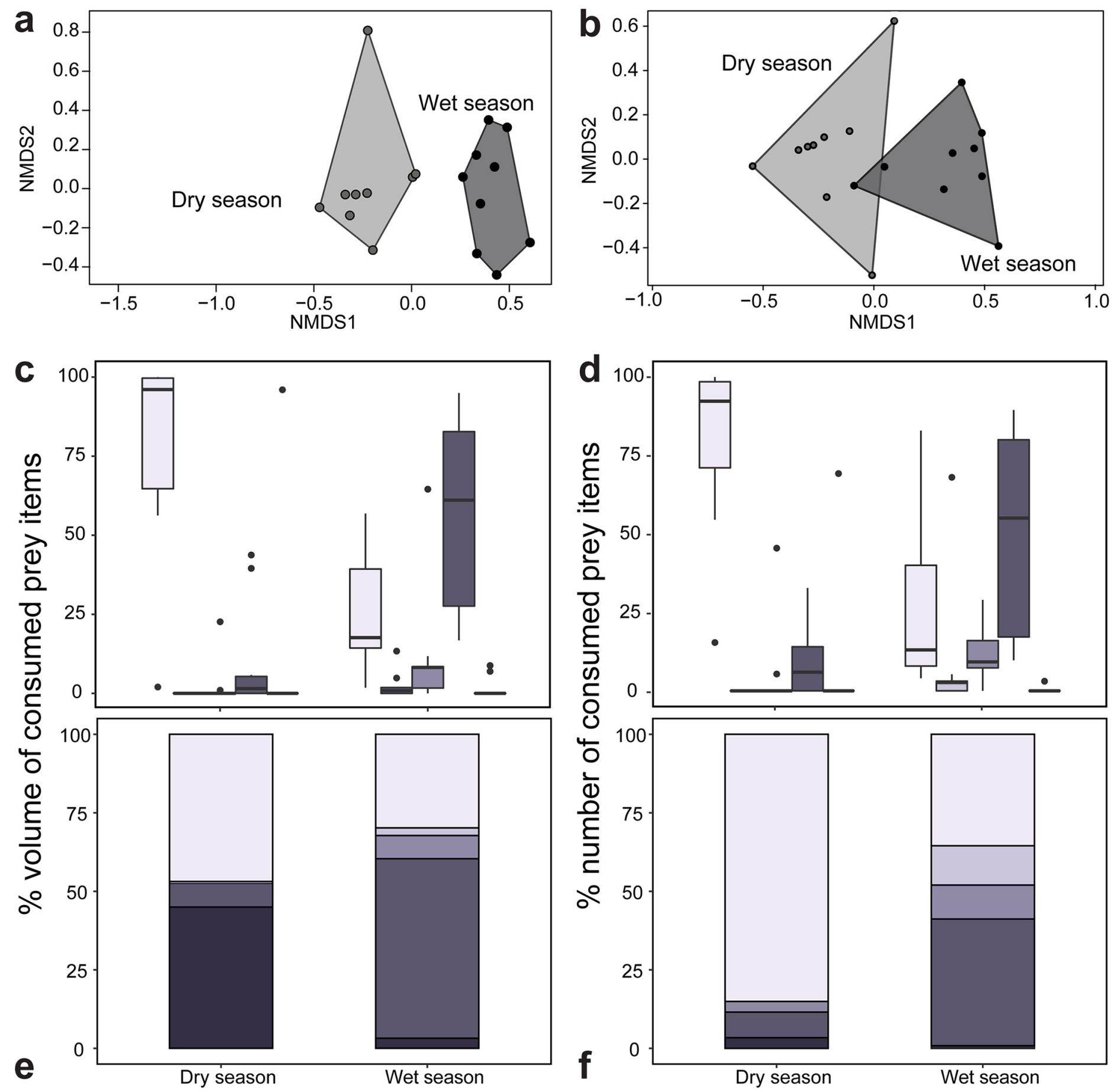

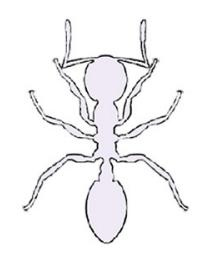

Ants

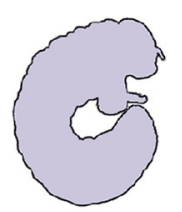

Insect larvae

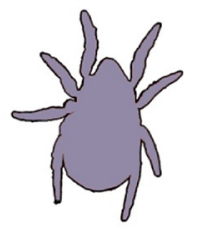

Mites

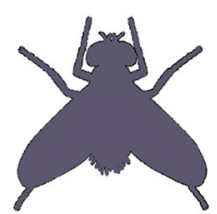

Other

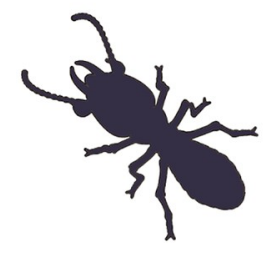

Termites 
Fig 2. The diet of the Climbing Mantella (Mantella laevigata) differs between dry and wet seasons. Non-metric multidimensional scaling (NMDS) biplots based on Bray-Curtis distances display diet differences between seasons using five prey item categories as input (ants, mites, larvae, termites and other prey items) based on (a) percent number and (b) percent volume of prey items. Below each NMDS plot is abundance in percent volume (c) and percent number (d) of each prey item category among seasonal groups, and individual distribution of prey item categories among seasonal groups (e, f).

https://doi.org/10.1371/journal.pone.0207940.g002

The quantity of ants consumed among wet and dry season groups in M. laevigata varied by both relative number (Fig $2 \mathrm{C}$ and $2 \mathrm{E}$, Table $1, \mathrm{~S} 1 \mathrm{Table}, \mathrm{U}=90, p=0.002$ ) and relative volume (Fig $2 \mathrm{D}$ and $2 \mathrm{~F}, \mathrm{U}=90, p=0.002$ ). Ants accounted for $84 \%$ of the total number of prey items in the dry season, but only $35 \%$ in the wet season. Most consumed ants for which we obtained CO1 sequence are from the subfamily Myrmicinae (95\%) and include the tribes Crematogastrini (genera Cataulacus and Tetramorium), Attini (genera Pheidole and Strumigenys) and Solenopsidini (genus Solenopsis) (Fig 3, S5 Table). In particular, most of the consumed ants that were successfully amplified (90.2\%) matched to ants in the genus Pheidole. Non-myrmicinae ants were rare but included a Paratrechina (99\% match to P. longicornis, the Longhorn Crazy Ant, Tribe Lasiini) and Ravavy MG001, from the subfamily Dolichoderinae (Tribe Tapinomini). Aided by the barcoded ant specimens, we also performed taxonomic identification of all whole ants by morphology (S3 Table). The three most common species identified were Pheidole sp. MG051, Pheidole sp. MGS128, and Pheidole nr. madecassa (Fig 3). Between seasons, consumption of these three ant species did not differ (Pheidole sp. MG051; $\mathrm{U}=36$, $p=0.7939$, Pheidole sp. MGS128; $\mathrm{U}=42, p=0.199$, Pheidole $\mathrm{nr}$. madecassa; $\mathrm{U}=42, p=0.199$ ).

Frogs collected in the wet season consumed more mites in both relative volume $(\mathrm{U}=13.5$, $p=0.004)$ and relative number $(\mathrm{U}=15.5, p=0.007)$ compared to frogs collected in the dry season (Fig 1C-1F, Table 1). Barcode information for arachnids is limited compared to ants and so classifications were restricted to Order for all specimens. Most of the consumed arachnids for which we obtained $\mathrm{CO} 1$ sequence are mites (Subclass Acari) from the Sarcoptiformes order (94.7\%) and a single mite from the Mesostigmata order (Fig 4, S6 Table). Several spiders were also recovered from the stomach contents of wet season frogs. Consumption of the three most consumed, genetically identifiable arachnid orders did not differ between seasons (Sarcoptiformes; $\mathrm{U}=4, p=0.5338$, Mesostigmata; $\mathrm{U}=2, p=0.999$, Araneae; $\mathrm{U}=1.5, p=0.729$ ).

Insect larvae made up a substantial portion of the stomach contents of frogs collected in the wet season but constituted no part of dry season frog diet (Fig 1A-1E; Table 1; S7 Table; volume: $\mathrm{U}=16.5, p=0.002$; number: $\mathrm{U}=16.5, p=0.002$ ). Most of these insect larvae were flies (45\%, Order Diptera), including many midge larvae (Family Ceratopogonidae), although some wood moth larvae (Order Lepidoptera, Family Crambidae) were also present. We grouped all other arthropods recovered from the stomach contents into an "other" category, in which we noted the presence of several beetles (Order Coleoptera), including a number of click beetles (Family Elateridae). Other arthropods included springtails (Collembola), parasitic wasps (Order Hymenoptera, Family Braconidae), termites, and barkflies (Order Psocoptera). Frogs collected in the wet season consumed more of these "other arthropods" in both volume $(\mathrm{U}=6, p=0.001)$ and number $(\mathrm{U}=9, p=0.002)$ compared to frogs collected in the dry season (Fig 1C-1F, Table 1). There were no significant differences in the abundance of the three most consumed, genetically identifiable "other" orders between wet and dry season frogs (Fig 5; Collembola; $\mathrm{U}=7, p=0.8026$, Coleoptera; $\mathrm{U}=13, p=0.2284$, Diptera; $\mathrm{U}=8, p=0.1$ ).

\section{Seasonal differences in alkaloid profiles}

We identified 41 alkaloids in M. laevigata that were present in at least half of the frogs included in this study (S4 Table). Several alkaloids are likely ant-derived [38] (S8 Table), including the following eight decahydroquinolines (DHQ), one tricyclic alkaloid and one 3,5 di-substituted 
Table 1. Broad diet characterization of wet and dry season groups of Mantella laevigata.

\begin{tabular}{|c|c|c|c|c|c|c|c|c|c|c|}
\hline & \multicolumn{5}{|l|}{$\%$ number } & \multicolumn{5}{|l|}{ \% volume } \\
\hline & ants & $\underline{\text { mites }}$ & larvae & termites & other & ants & $\underline{\text { mites }}$ & $\underline{\text { larvae }}$ & $\underline{\text { termites }}$ & other \\
\hline Dry & 85.1 & 3.4 & 0 & 3.4 & 8.1 & 46.9 & 0.5 & 0 & 45.0 & 7.6 \\
\hline Wet & 35.5 & 10.8 & 12.5 & 0.8 & 40.3 & 29.9 & 7.4 & 24 & 3.2 & 57.2 \\
\hline $\mathbf{U}$ & 90 & 15.5 & 16.5 & 44 & 9 & 90 & 13.5 & 16.5 & 44 & 6 \\
\hline $\mathbf{p}$ & 0.002 & 0.007 & 0.002 & 0.541 & 0.002 & 0.002 & 0.004 & 0.002 & 0.541 & 0.001 \\
\hline
\end{tabular}

Diet analysis of different prey types consumed by Mantella laevigata in the dry $(\mathrm{N}=11)$ and wet $(\mathrm{N}=9)$ seasons. See $\mathrm{S} 1 \mathrm{Table}$ for full data set. Abbreviations: $U$, $\mathrm{U}$ test statistic and $p$-value from Mann-Whitney $\mathrm{U}$ tests.

https://doi.org/10.1371/journal.pone.0207940.t001

pyrrolizidine (3,5-P): 189 DHQ,193D DHQ, 195A DHQ, 195J DHQ, 209A DHQ, 211A DHQ, 211K DHQ, 219A DHQ, 2370 Tricyclic, and 239K 3,5-P. Others are likely mitederived [38] (S8 Table), including pumiliotoxins (PTX): 197G 5,8,6-I (5,6,8-trisubstituted indolizidine), 211L 5,8,6-I, 225K 5,8,6-I, 239W 5,8,6-I, 267W 5,8,6-I, 253F PTX, 275E 5,8,6-I $2^{\text {nd }}$ Isomer, 291E DeoxyPTX $1^{\text {st }}$ Isomer, 305A aPTX (allopumiliotoxin), 307A PTX pumiliotoxin A minor isomer, 307G PTX, 321B hPTX (homopumiliotoxin), 321D hPTX 1stIsomer, 323A PTX pumiliotoxin $\mathrm{B}$, and 337B $\mathrm{hPTX}$.

\section{a Pheidole sp. MG051 b Pheidole sp. MGS1281 C Pheidole nr. madecassa}

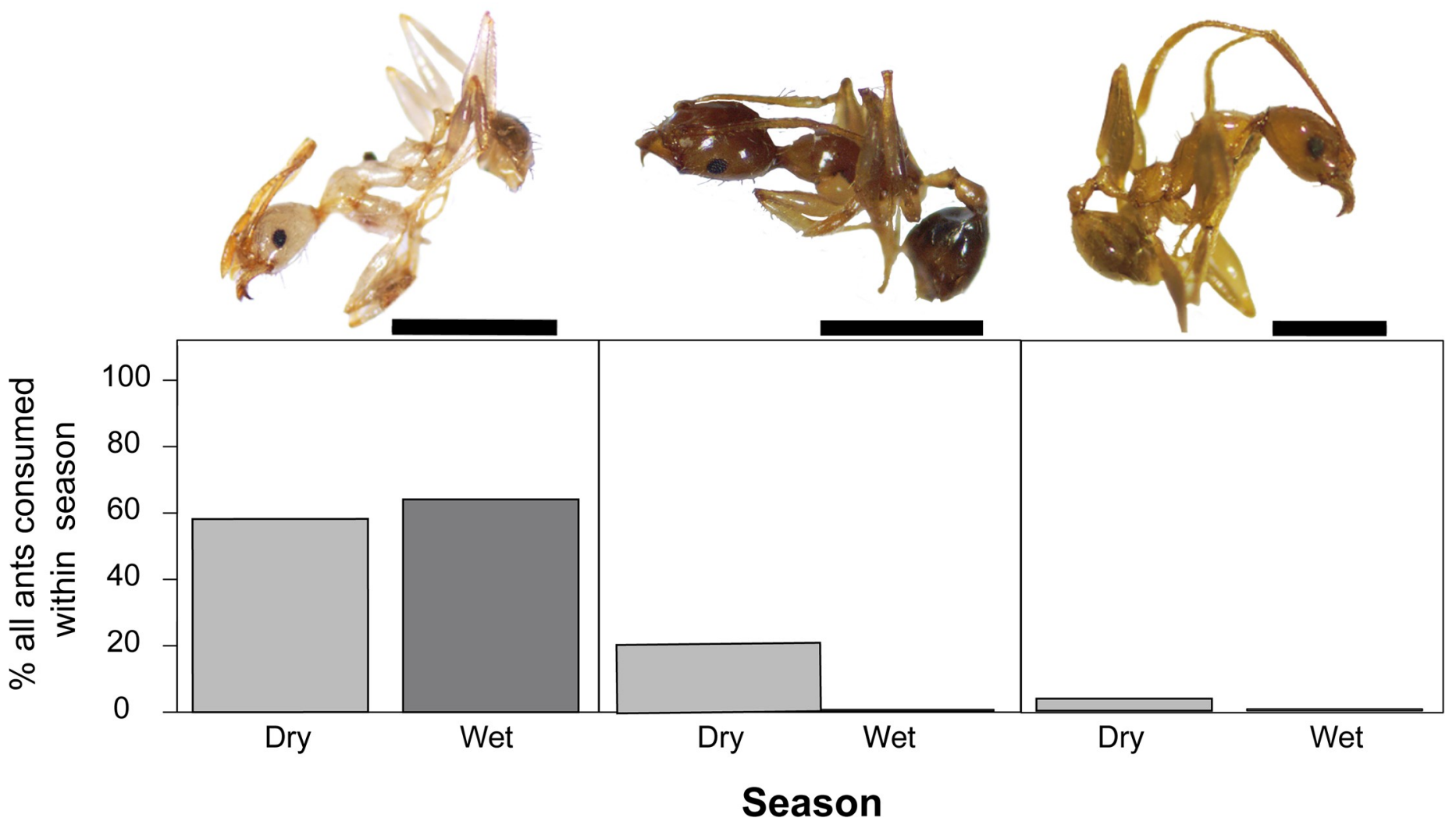

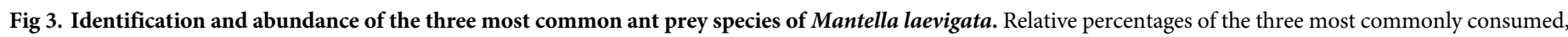

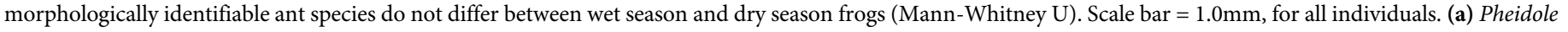
sp. MG051 (b) Pheidole sp. MGS128, (c) Pheidole nr. madecassa.

https://doi.org/10.1371/journal.pone.0207940.g003 


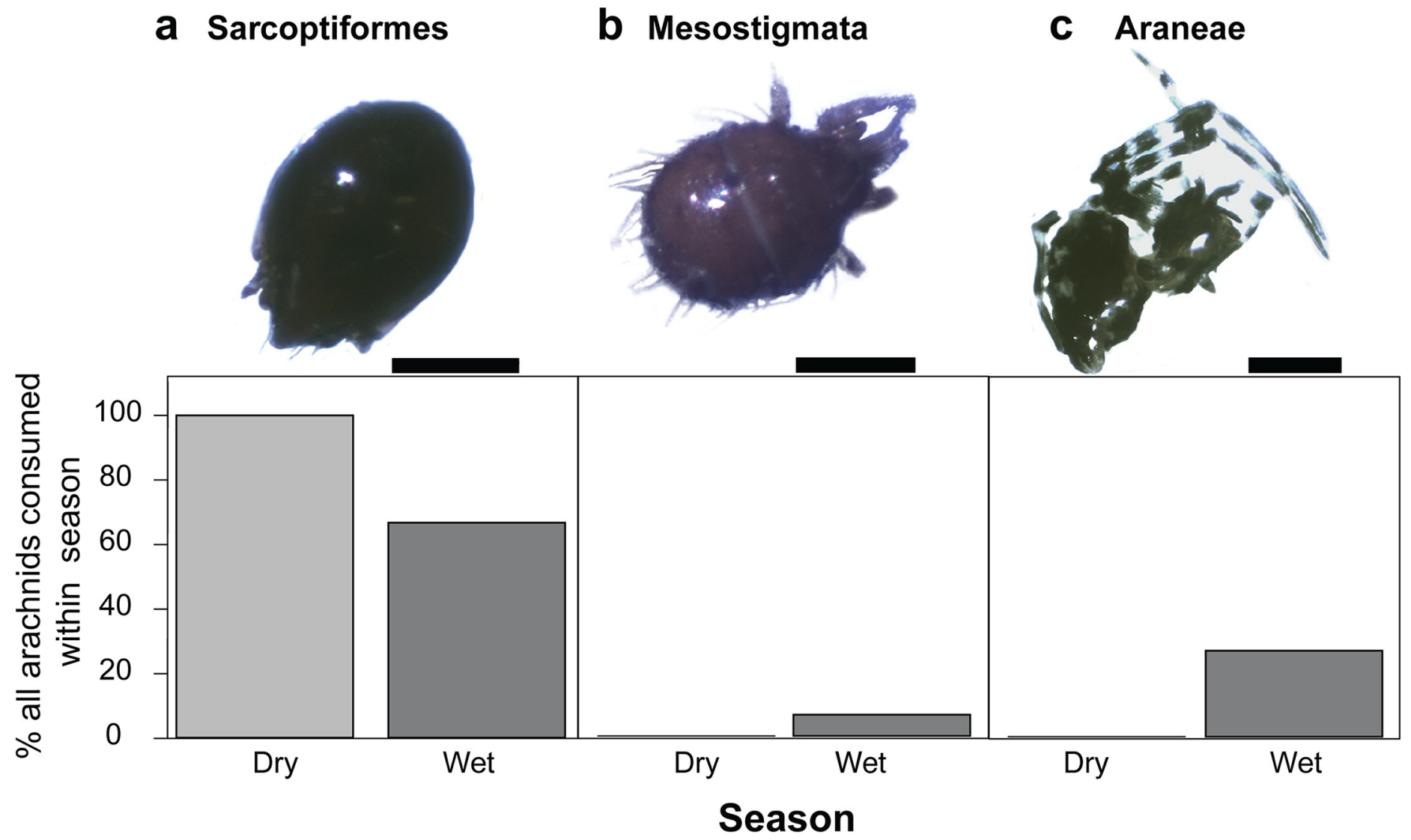

Fig 4. Identification and abundance of the three most common arachnid prey species of Mantella laevigata. Relative percentages of the three most commonly consumed, genetically identifiable arachnid orders do not differ between wet season and dry season frogs (Mann-Whitney U). (a) Sarcoptiformes; scale bar $=0.5 \mathrm{~mm}$. (b) Mesostigmata; scale bar $=0.25 \mathrm{~mm}$. (c) Araneae; scale bar $=0.25 \mathrm{~mm}$.

Frogs collected in different seasons had no overall differences in alkaloid profiles (NMDS analysis, $\mathrm{F}=1.279 ; \mathrm{p}=0.22$; Fig $6 \mathrm{~A}$ ). Overall wet season frogs appear less variable in their alkaloid profiles, clustering as if their chemical profiles are a subset of dry season alkaloids, but this variation between seasonal groups was not statistically significant $(\mathrm{R}=0.03497 ; \mathrm{p}=0.266)$. However, seven individual alkaloids differed significantly in abundance between wet and dry season groups (Mann-Whitney U tests, Fig 5B): 211A DHQ, $(\mathrm{U}=16.5, p=0.01), 211 \mathrm{~K}$ DHQ, $(\mathrm{U}=\mathbf{1 2}, \boldsymbol{p}=\mathbf{0 . 0 0 4}), 211 \mathrm{~L} 5,8,6-\mathrm{I}(\mathrm{U}=11$, $p=0.003), 253 \mathrm{~F}$ PTX $(\mathrm{U}=13, p=0.004), 275 \mathrm{E} 5,6,8-\mathrm{I}(\mathrm{U}=17, p=0.01), 305 \mathrm{~A}$ aPTX $(\mathrm{U}=80, p=0.02)$, and 323A PTX $(\mathrm{U}=9, p=0.001)$. Six of these alkaloids were higher in abundance in wet season frogs compared to dry season frogs.

\section{Discussion}

We showed that arthropod consumption differed between groups of $M$. laevigata from the wet and dry seasons both within and across prey types. Although there were no overall differences in the number and types of alkaloids present between seasons, seven unique alkaloids differed in abundance between seasons with the majority more abundant in the wet season. We discuss our diet and chemical results in the context of studies in other poison frogs and link these two measurements together in the context of trophic ecology and environmental change. 
a Collembola

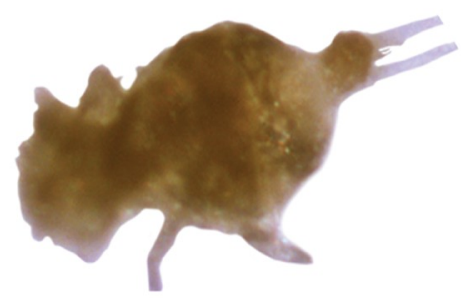

b Coleoptera

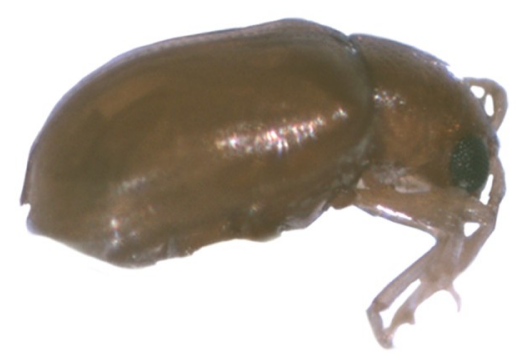

C Diptera

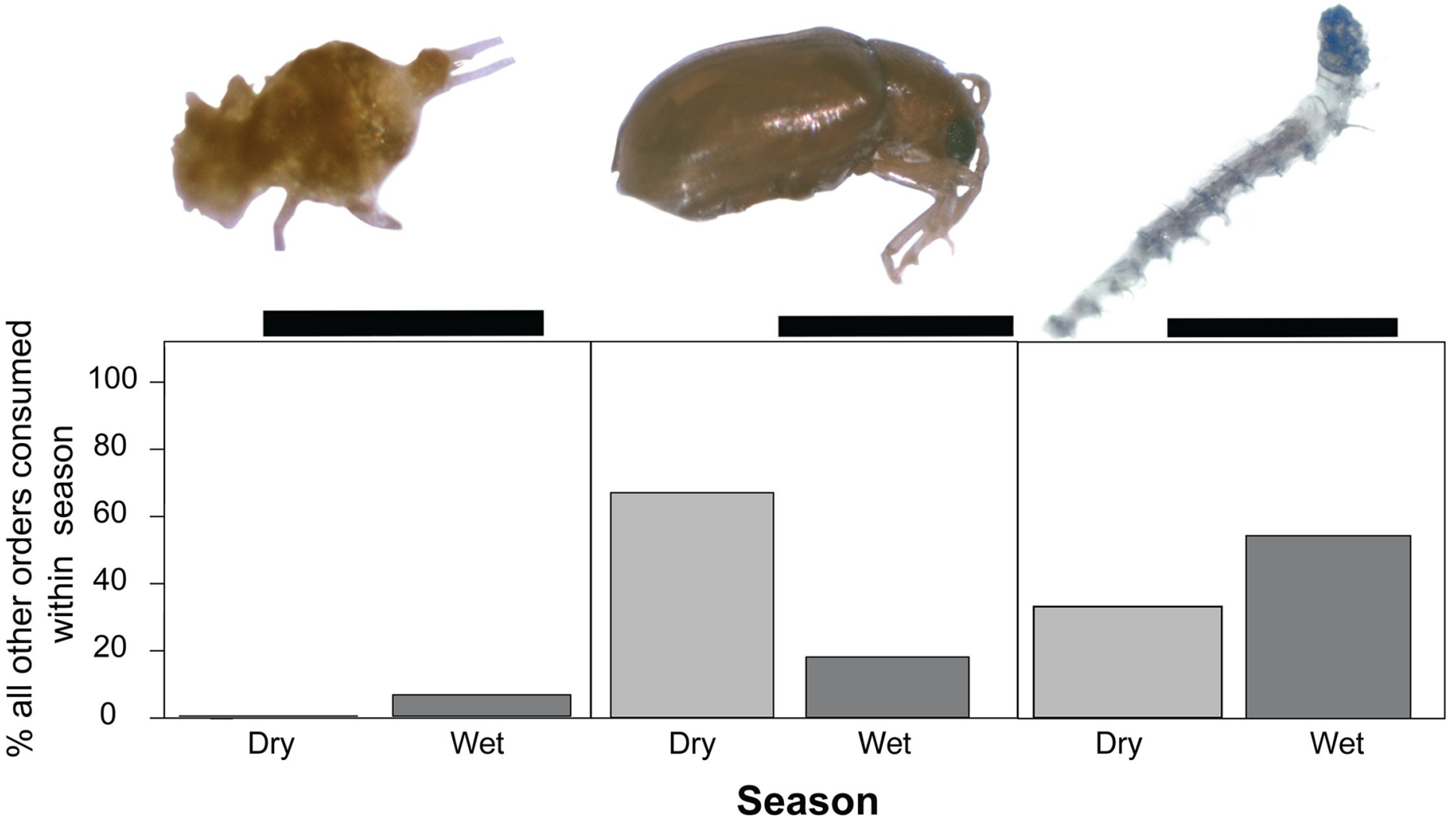

Fig 5. Identification and abundance of the three most common other prey species of Mantella laevigata. Relative percentages of the three most commonly consumed, genetically identifiable other (non-ant and non-arachnid) prey items does not differ between wet season and dry season frogs (Mann-Whitney U). (a) Collembola; scale bar $=0.5 \mathrm{~mm}$ (b) Coleoptera; scale bar $=1.0 \mathrm{~mm}$ (c) Diptera; scale bar $=1.0 \mathrm{~mm}$.

https://doi.org/10.1371/journal.pone.0207940.g005

\section{Diet of the Climbing Mantella compared to other poison frogs}

The diet of poison frogs has been intensely studied since it was demonstrated that poison frogs acquire their alkaloids from their diet. Our study is the first in mantellids to compare diet across wet and dry seasons and found that frogs in the wet season have a broader diet that includes an abundance of insect larvae, while frogs in the dry season eat more ants. Other studies have examined the diet and food preferences of Mantella poison frogs and have found variation between study sites and species. Two studies across numerous Mantella species ( $M$. baroni, bernhardi, betsileo, haraldmeieri, laevigata, madagascariensis, and nigricans) showed ants comprised an average of $27-91 \%$ of prey volume in the wet season $[26,39]$. In contrast, a study with the Golden Mantella (M. aurantiaca) showed ants made up a low percentage of the diet (11-15\%) and mites a higher percentage (18-34\%) in the wet season [27]. A food preference assay has shown that $M$. laevigata will readily eat any small prey items available in the leaf litter (rather than having a continuous and active preference for ants and mites) [26].

Together, these observations suggest that some mantellids-including our focal species-are not ant-specialists. Despite the overall lower percentage of ants in the diet of M. aurantiaca and $M$. laevigata in the wet season, both species showed high selectivity for Pheidole ants among the ants they did consume [27]. Specifically, over half of the consumed ants in both the wet and dry seasons were a single ant species, Pheidole sp. MG051 (Fig 3). This suggests M. laevigata frogs may prefer certain types of ants despite not specializing on this prey type. Alternatively, 

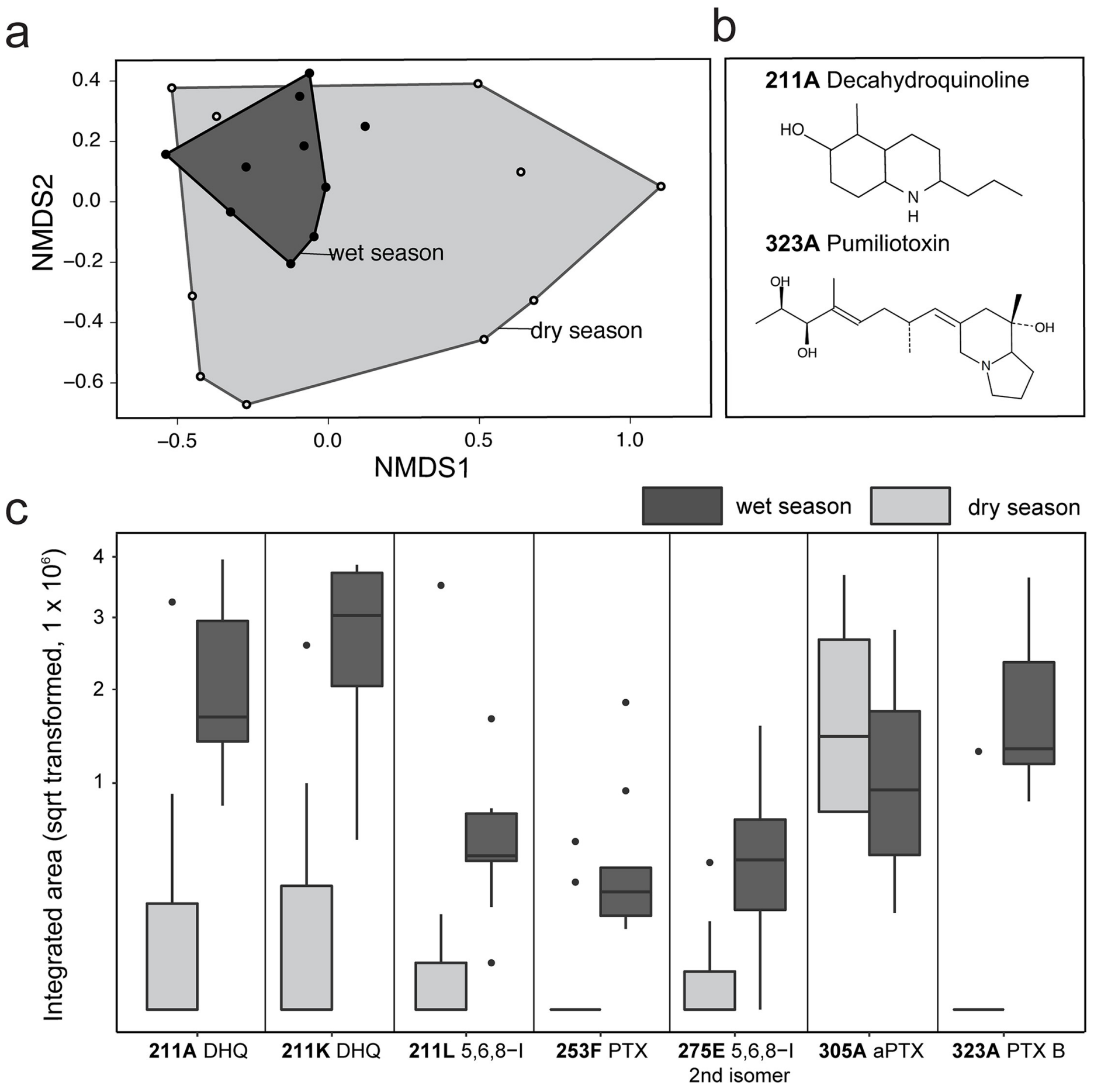

Alkaloid

Fig 6. Seasonal comparison of chemical defenses in Mantella laevigata. (a) Non-metric multidimensional scaling (NMDS) biplots based on Bray-Curtis distances show overlap of alkaloid profiles between wet and dry season frogs. (b) Chemical structures of two alkaloids that differ in abundance between collected in the wet and dry season are shown. (c) Abundance of seven alkaloids that are significantly different in $M$. laevigata frogs collected in the dry and wet seasons. Box plots show the median, first and third quartiles, whiskers ( \pm 1.5 interquartile range) and outliers (black dots); PTX = Pumiliotoxin; DHQ = Decahydroquinoline;

5,6,8-I = 5,6,8-trisubstituted indolizidine.

https://doi.org/10.1371/journal.pone.0207940.g006 
there may be more Pheidole ants present in the leaf litter and the frogs are sampling the most abundant species. Detailed leaf litter and prey preference assays are needed to distinguish between these alternative explanations. In summary, our observations in M. laevigata are consistent with previous studies in M. laevigata and M. aurantiaca, and demonstrate that some $M$. laevigata are active foragers that will readily eat nutritious prey items like flies or insect larvae. They appear to retain a preference for certain types of ants over others, although testing this hypothesis in future studies would require data on prey availability from leaf litter assays.

Ecological studies in tropical habitats have shown that arthropod diversity and abundance change in the leaf litter based on moisture [31]. Although we did not directly survey leaf litter arthropods in this study, we suggest that seasonal variation in rainfall influences the leaf litter arthropods available for frogs to prey on. While many studies have reported that Neotropical poison frogs in the Dendrobatidae family are selective for the ants and mites that typically make up $80-90 \%$ of their diet $[13,25]$, the relative proportion of these prey categories can vary by season. For example, in the Strawberry poison frog Oophaga pumilio, the relative proportion of ants and mites varied from $30 \%$ ants / 65\% mites in summer months to $75 \%$ ants / $10 \%$ mites in winter months [25]. A study focusing specifically on seasonal variation in poison frog diet found that French Guianese Dendrobates tinctorius had a more diverse arthropod diet in the wet season compared to the dry season [40]. A study focusing on M. aurantiaca supports this idea in mantellids [27] where there were a large number of flies (Diptera) and springtails (Collembola) among consumed prey items in the wet season. Our findings that M. laevigata consumed a greater diversity of arthropods in the wet season align with these studies and support the idea that increased arthropod diversity in the wet season leads to increased diet diversity in both dendrobatids and mantellids. In contrast to M. laevigata, however, O. pumilio and $D$. tinctorius still had an ant-heavy diet in both the wet and dry seasons lending further support to the assertion that $M$. laevigata are not strict ant specialists compared to dendrobatids.

In addition to variation in prey availability, seasonal changes in diet may also result from seasonal behavioral differences. Behavior may change seasonally based on the microhabitats frogs inhabit as humidity and temperature change. In our study, we found that dry season $M$. laevigata frogs consumed $44 \%$ more prey than wet season frogs (S1 Table). During the warmer dry season, we observed more frogs foraging in places that were more shaded, and likely cooler, such as under water pipes and decaying logs at our field sites, and these areas may also harbor more arthropods. Thus, seasonal diet changes may result from changes in prey availability in conjunction with behavioral changes.

\section{Defensive chemicals in the climbing mantella}

We reported 41 alkaloids that were present in at least $50 \%$ of the individuals in this study. Many alkaloids overlap with those that have been reported previously in mantellids and other Neotropical poison frogs ( $\$ 4$ Table). Ten alkaloids have never been reported in a Mantella species to our knowledge [28, 39, 41], and include one unclassified alkaloid (153B), three decahydroquinolines $(209 \mathrm{~A}, 211 \mathrm{~A}, 211 \mathrm{~K})$, a 5,6,8-trisubstituted indolizidine (211L), a 5,8-disubstituted indolizidine (225D), an izidine (233B), 3,5-disubstituted indolizidines (237E), a tricyclic (237O), and a quinoline (380). Most of these alkaloids had previously only been found in dendrobatid poison frogs, many of which had been reported in Panamanian $O$. pumilio [16, 29]. The tricyclic $\mathbf{2 3 7 0}$ alkaloid had previously been reported in a bufonid [42]. Our findings add support to previous reports of convergent evolution of alkaloid sequestration in Malagasy and Neotropical poison frogs [11].

Although we found significant seasonal variation in the diet of $M$. laevigata, we did not find drastic seasonal variation in alkaloid profiles in terms of the number and quantity present. 
There is a trend for wet season frogs to have less variable alkaloid profiles than dry season frogs, but this variance is not statistically significant (Fig 6). These observations are in contrast to another study that analyzed seasonal variation in alkaloids in dendrobatid poison frogs, where Saporito et al [16] found seasonal variation in the absence/presence of alkaloids in Panamanian O. pumilio. However, the O. pumilio study included many collection sites and individuals whereas our study was focused on a single population of $M$. laevigata and had a smaller sample size. Thus, seasonal variation in concert with geographical variation may be contributing to greater differences in O. pumilio than those we observed in M. laevigata. Moreover, adult poison frogs can retain their alkaloids for months and even years in captivity [43], and the ability to retain alkaloids for long periods of time could also explain the buffering effect we see in the present study, where frog alkaloid profiles look similar across seasons despite changes in diet. Based on the changes in abundance of specific alkaloids, we hypothesize that seasonal changes in diet do indeed influence alkaloid profiles (i.e alkaloid abundance), but that overall alkaloid profiles (i.e. alkaloid presence/absence) are stable due to long-term alkaloid retention across seasons. Research involving more frequent tracking of overall alkaloid abundance in frogs is needed in order to gain a deeper understanding of alkaloid retention and the temporal relationship between alkaloid consumption, storage, and potency, especially in the context of natural seasonal variation.

\section{Connecting diet to chemical defense in the context of seasonal variation}

Testing the association between alkaloid diversity and stomach contents is difficult due to the limited sampling of frogs in this study. Here we remark on our observations between prey items recovered from the stomach contents and published alkaloid profiling in these arthropods. The bulk of alkaloids found in M. laevigata from the present study originate from myrmicine ants and have previously been found in both dendrobatids and mantellids [6]. Many decahydroquinolines were found in both seasonal groups, most of which are known to originate from myrmicine ants $[12,14]$. Myrmicine ants from the genus Pheidole account for the majority of ants that $M$. laevigata consume across seasons and this suggests that $M$. laevigata may rely on ants for their chemical defenses. Of the seven alkaloids that were significantly different in abundance between seasons, three have a proposed ant origin (S8 Table). Several ants recovered from the M. laevigata diet have been documented to contain alkaloids, including Tetramorium ants that carry pumiliotoxins and 5,8 indolizidines [11] and Paratrechina ants that carry a variety of alkaloids [44]. Some Solenopsis specimens were also recovered from the stomach contents, and these ants have been well-studied in the context of fire ant defensive alkaloids [45]. Both the number and volume of ants consumed by $M$. laevigata varied between seasons and this could explain some of the seasonal variation in alkaloid abundance. Given most of the ants recovered from the stomach contents were from the genus Pheidole, a more systematic characterization of the chemical composition of these ants could help to confirm this ant genus as a dietary source of alkaloids in poison frogs. Such a study could also reveal dietary preferences at the morphospecies level, as have been reported in a previous study of $M$. aurantiaca [27], which could be correlated with the acquisition of specific alkaloids. Strong selectivity for Pheidole ants even in the absence of an overall dietary specialization on ants may allow for simultaneous diet diversification and alkaloid maintenance.

Mites are known to be a rich dietary source of alkaloids in poison frogs [46]. At least 80 alkaloids have been documented from extracts of oribatid mites [15, 46, 47], corresponding to 11 of the 24 classes of alkaloids found in dendrobatid poison frogs. We found three families of oribatid mites known to contain alkaloids in M. laevigata stomach contents: Galumnidae, Scheloribatidae, and Oppiidae. Tricyclic alkaloids have been reported in Galumnidae mites 
while pumiliotoxins have been reported in both Schelorbatidae and Oppiidae mite families $[46,48]$. Thus, although mites made up a small proportion of the M. laevigata diet, they are likely an important source of alkaloids and it is notable that their number and volume in the stomach contents differed across seasons. Out of the seven alkaloids that significantly varied in abundance in M. laevigata across seasons, three are thought to have a mite origin (5,6,8-trisubstituted indolizidine 275E, allopumiliotoxin 305A, and pumilitotoxin B 323A, see S8 Table) [6]. Compared to ants, little is known about the taxonomy and chemistry of mites and more work is needed on this group of organisms to better understand the trophic chain of alkaloid sequestration.

Although many alkaloid classes have a proposed ant or mite origin [6], many alkaloids have not yet been documented in specific leaf litter arthropods and generally very little is known about which specific species of ants, mites, or other arthropods carry the alkaloids found in poison frogs. Of the 41 alkaloids documented in M. laevigata in the present study, 20 have an unknown origin. Further chemical analyses are needed to trace the origin of these alkaloids to specific arthropod species in the trophic chain. In addition, analyses of prey items recovered from stomach contents represent only a snapshot in time and long-term monitoring of diet is needed in order to make conclusions about alkaloid origins in arthropods. Future studies that combine long-term diet monitoring with behavioral testing and chemical analyses of arthropods from the leaf litter will shed light on how prey abundance interacts with prey preference to drive variation in poison frog alkaloid profiles.

\section{Conclusions}

We found substantial variation in the M. laevigata diet between seasons. Although we used both molecular and morphological methods to assay diet in the present study, these results are only a snapshot in time and repeated sampling of the same individuals by stomach flushing or fecal barcoding would be a valuable step forward in understanding diet variation a finer scale.

Moreover, leaf litter studies coupled with diet analyses would be valuable in assessing the intersection of prey preference, prey availability, and frog behavior. Finally, although there were differences in the abundance of specific alkaloids between frogs collected in the wet and dry season, overall alkaloid profiles were similar across seasons. The ability for adult poison frogs to retain their alkaloids for years in captivity coupled with our observations of cross-seasonal stability in alkaloid profiles suggests that poison frog defenses are buffered against acute environmental changes. Nonetheless, changes in alkaloid abundance even at the short timescale we consider here suggest that more extreme, long-term shifts in temperature and humidity will impact poison frog alkaloid abundance and continued long-term monitoring of poison frog populations is warranted. Given the unique and fascinating link between arthropod diversity and poison frog biology, poison frogs may serve as a useful model for understanding the ecological consequences of global environmental change across trophic levels.

\section{Supporting information}

S1 Fig. Environmental information for Sambava, Madagascar. (a) Sambava is roughly 150 $\mathrm{km}$ northeast of Nosy Mangabe. Precipitation (blue) and temperature (orange) are shown for 2015 (b) and 2016 (c); field work time is indicated in red. Environmental data was obtained from: https://www.historique-meteo.net/afrique/madagascar/sambava/

(TIF) 
S1 Table. Diet data for each Mantella laevigata frog. The absolute and relative volume and number for each prey category for each frog is listed and summarized.

(XLSX)

S2 Table. Arthropod sample barcode information. The details for each cytochrome oxidase 1 barcoded non-ant arthropod is listed with the sample ID, the prey type, and information on the top BLAST hit including the species name, percent identity, and $\mathrm{E}$ value.

(DOCX)

S3 Table. Morphological and genetic identification of ant specimens. For all morphologically or genetically identifiable ant specimens found in M. laevigata stomach contents across wet and dry seasons, we list the sample ID, species name, BOLD and Genbank database IDs and percent matches to these IDs For Genbank-matched individuals, BLASTn hit, specimen Genbank accession number, percent identity and $\mathrm{E}$ value are also listed.

(XLSX)

S4 Table. Abundance of the 41 alkaloids present in at least half of Mantella laevigata individuals in this study. Abundance is represented by the integrated area under the curve (no units) from the mass spectrometry ion chromatogram for each alkaloid and frog.

(XLSX)

S5 Table. Detailed sample information for barcoded ant species. Both morphologically and genetically identifiable ant specimens with exemplar photos representing respective taxonomic groups across seasonal groups are listed with their sample ID's.

(DOCX)

S6 Table. Detailed sample information for barcoded arachnid species. Genetically identifiable arachnid specimens with exemplar photos representing respective taxonomic groups across seasonal groups are listed with their sample ID's.

(DOCX)

S7 Table. Detailed sample information for barcoded “other" prey items. Genetically identifiable ant specimens with exemplar photos representing respective taxonomic groups across seasonal groups are listed with their sample ID's.

(DOCX)

S8 Table. Detailed literature information on alkaloids. For each of the 41 identified alkaloids, we list the proposed arthropod origin and whether the alkaloid has been previously found in other mantellid species or other anurans.

(DOCX)

\section{Acknowledgments}

We would like to thank the University of Antananarivo, ICTE/MICET, and Madagascar National Park (MNP) for providing logistical assistance. We thank Hadley Weiss for technical assistance. We are very grateful to the Malagasy authorities for research permits. We would like to thank the local MNP guides Béonique, Donné, Clotric, and Marcel for their help and company.

\section{Author Contributions}

Conceptualization: Miguel Vences, Lauren A. O’Connell.

Data curation: Nora A. Moskowitz, Eva K. Fischer, Charles Vidoudez, David A. Donoso. 
Formal analysis: Nora A. Moskowitz, Charles Vidoudez.

Funding acquisition: Andrew W. Murray, Lauren A. O'Connell.

Investigation: Alexandre B. Roland, Eva K. Fischer, Ndimbintsoa Ranaivorazo, Marianne T. Aguilar, Sophia M. Caldera, Jacqueline Chea, Miruna G. Cristus, Jett P. Crowdis, Bluyé DeMessie, Caroline R. desJardins-Park, Audrey H. Effenberger, Felipe Flores, Michael Giles, Emma Y. He, Nike S. Izmaylov, ChangWon C. Lee, Nicholas A. Pagel, Krystal K. Phu, Leah U. Rosen, Danielle A. Seda, Yong Shen, Santiago Vargas, Eden Abebe, David A. Donoso.

Methodology: Alexandre B. Roland, Charles Vidoudez.

Project administration: Nora A. Moskowitz, Lauren A. O'Connell.

Resources: Andrew W. Murray, Sunia A. Trauger, Miguel Vences.

Supervision: Ndimbintsoa Ranaivorazo, Andrew W. Murray, Sunia A. Trauger, Miguel Vences, Lauren A. O'Connell.

Validation: Charles Vidoudez.

Writing - original draft: Nora A. Moskowitz, Lauren A. O'Connell.

Writing - review \& editing: Alexandre B. Roland, Eva K. Fischer, Charles Vidoudez, Marianne T. Aguilar, Sophia M. Caldera, Jacqueline Chea, Miruna G. Cristus, Jett P. Crowdis, Bluyé DeMessie, Caroline R. desJardins-Park, Audrey H. Effenberger, Felipe Flores, Michael Giles, Emma Y. He, Nike S. Izmaylov, ChangWon C. Lee, Nicholas A. Pagel, Krystal K. Phu, Leah U. Rosen, Danielle A. Seda, Yong Shen, Santiago Vargas, Andrew W. Murray, Eden Abebe, Sunia A. Trauger, David A. Donoso, Miguel Vences.

\section{References}

1. Nicolas $P$, Mor A. Peptides as weapons against microorganisms in the chemical defense system of vertebrates. Annual Reviews in Microbiology. 1995; 49(1):277-304.

2. Pawlik JR. Marine invertebrate chemical defenses. Chemical Reviews. 1993; 93(5):1911-22.

3. Savitzky AH, Mori A, Hutchinson DA, Saporito RA, Burghardt GM, Lillywhite HB, et al. Sequestered defensive toxins in tetrapod vertebrates: principles, patterns, and prospects for future studies. Chemoecology. 2012; 22(3):141-58. https://doi.org/10.1007/s00049-012-0112-z PMID: 22904605

4. Daly JW, Highet RJ, Myers CW. Occurrence of skin alkaloids in non-dendrobatid frogs from Brazil (Bufonidae), Australia (Myobatrachidae) and Madagascar (Mantellinae). Toxicon. 1984; 22(6):905-19. PMID: 6523513

5. Saporito RA, Donnelly MA, Spande TF, Garraffo HM. A review of chemical ecology in poison frogs. Chemoecology. 2012; 22(3):159-68.

6. Daly JW, Spande TF, Garraffo HM. Alkaloids from amphibian skin: a tabulation of over eight-hundred compounds. Journal of Natural Products. 2005; 68(10):1556-75. https://doi.org/10.1021/np0580560 PMID: 16252926

7. Saporito RA, Spande TF, Garraffo HM, Donnelly MA. Arthropod alkaloids in poison frogs: a review of the dietary hypothesis. Heterocycles. 2009; 79(1):277-97.

8. Santos JC, Tarvin RD, O'Connell LA. A review of chemical defense in poison frogs (Dendrobatidae): ecology, pharmacokinetics, and autoresistance. Chemical Signals in Vertebrates 13: Springer; 2016. p. 305-37.

9. Daly JW, Garraffo HM, Hall GS, Cover JF Jr. Absence of skin alkaloids in captive-raised Madagascan mantelline frogs (Mantella) and sequestration of dietary alkaloids. Toxicon. 1997; 35(7):1131-5. PMID: 9248011

10. Daly JW, Garraffo HM, Spande TF, Jaramillo C, Rand AS. Dietary source for skin alkaloids of poison frogs (Dendrobatidae)? Journal of Chemical Ecology. 1994; 20(4):943-55. https://doi.org/10.1007/ BF02059589 PMID: 24242207 
11. Clark VC, Raxworthy CJ, Rakotomalala V, Sierwald P, Fisher BL. Convergent evolution of chemical defense in poison frogs and arthropod prey between Madagascar and the Neotropics. Proceedings of the National Academy of Sciences of the United States of America. 2005; 102(33):11617-22. https:// doi.org/10.1073/pnas.0503502102 PMID: 16087888

12. Daly JW, Garraffo HM, Jain P, Spande TF, Snelling RR, Jaramillo C, et al. Arthropod-frog connection: decahydroquinoline and pyrrolizidine alkaloids common to microsympatric myrmicine ants and dendrobatid frogs. Journal of Chemical Ecology. 2000; 26(1):73-85.

13. Darst CR, Menéndez-Guerrero PA, Coloma LA, Cannatella DC. Evolution of dietary specialization and chemical defense in poison frogs (Dendrobatidae): a comparative analysis. The American Naturalist. 2004; 165(1):56-69. https://doi.org/10.1086/426599 PMID: 15729640

14. Jones TH, Gorman JS, Snelling RR, Delabie JH, Blum MS, Garraffo HM, et al. Further alkaloids common to ants and frogs: decahydroquinolines and a quinolizidine. Journal of Chemical Ecology. 1999; 25 (5):1179-93.

15. McGugan JR, Byrd GD, Roland AB, Caty SN, Kabir N, Tapia EE, et al. Ant and mite diversity drives toxin variation in the Little Devil Poison frog. Journal of Chemical Ecology. 2016; 42(6):537-51. https:// doi.org/10.1007/s10886-016-0715-x PMID: 27318689

16. Saporito RA, Donnelly MA, Garraffo HM, Spande TF, Daly JW. Geographic and seasonal variation in alkaloid-based chemical defenses of Dendrobates pumilio from Bocas del Toro, Panama. Journal of Chemical Ecology. 2006; 32(4):795-814. https://doi.org/10.1007/s10886-006-9034-y PMID: 16718571

17. Summers $\mathrm{K}$, Clough $\mathrm{ME}$. The evolution of coloration and toxicity in the poison frog family (Dendrobatidae). Proceedings of the National Academy of Sciences. 2001; 98(11):6227-32.

18. Roelants K, Gower DJ, Wilkinson M, Loader SP, Biju S, Guillaume K, et al. Global patterns of diversification in the history of modern amphibians. Proceedings of the National Academy of Sciences. 2007; 104(3):887-92.

19. Daly JW, Gusovsky F, McNeal ET, Secunda S, Bell M, Creveling CR, et al. Pumiliotoxin alkaloids: a new class of sodium channel agents. Biochemical Pharmacology. 1990; 40(2):315-26. PMID: 2165404

20. Daly JW, Nishizawa Y, Padgett WL, Tokuyama T, McCloskey PJ, Waykole L, et al. Decahydroquinoline alkaloids: Noncompetitive blockers for nicotinic acetylcholine receptor-channels in pheochromocytoma cells and Torpedo electroplax. Neurochemical Research. 1991; 16(11):1207-12. PMID: 1815136

21. Lovenberg T, Daly J. Histrionicotoxins: effects on binding of radioligands for sodium, potassium, and calcium channels in brain membranes. Neurochemical Research. 1986; 11(11):1609-21. PMID: 2446155

22. Tarvin RD, Santos JC, O'Connell LA, Zakon HH, Cannatella DC. Convergent substitutions in a sodium channel suggest multiple origins of toxin resistance in poison frogs. Molecular biology and evolution. 2016; 33(4):1068-81. https://doi.org/10.1093/molbev/msv350 PMID: 26782998

23. Vences $M$, Glaw F, Böhme W. Evolutionary correlates of microphagy in alkaloid-containing frogs (Amphibia: Anura). Zoologischer Anzeiger 1998; 236:217-30.

24. Caldwell JP. The evolution of myrmecophagy and its correlates in poison frogs (Family Dendrobatidae). Journal of Zoology. 1996; 240(1):75-101.

25. Donnelly MA. Feeding patterns of the strawberry poison frog, Dendrobates pumilio (Anura: Dendrobatidae). Copeia. 1991:723-30.

26. Vences M, Kniel C. Mikrophage und myrmecophage Ernaehrungs-spezialisierung bei madagassischen Giftfroeschen der Gattung Mantella. Salamandra. 1998; 34(3):245-54.

27. Woodhead C, Vences M, Vieites DR, Gamboni I, Fisher BL, Griffiths RA. Specialist or generalist? Feeding ecology of the Malagasy poison frog Mantella aurantiaca. The Herpetological Journal. 2007; 17 (4):225-36.

28. Andriamaharavo NR, Garraffo HM, Spande TF, Giddings L-A, Vieites DR, Vences M, et al. Individual and geographic variation of skin alkaloids in three swamp-forest species of Madagascan poison frogs (Mantella). Journal of Chemical Ecology. 2015; 41(9):837-47. https://doi.org/10.1007/s10886-0150616-4 PMID: 26329921

29. Saporito RA, Donnelly MA, Jain P, Garraffo HM, Spande TF, Daly JW. Spatial and temporal patterns of alkaloid variation in the poison frog Oophaga pumilio in Costa Rica and Panama over 30 years. Toxicon. 2007; 50(6):757-78. https://doi.org/10.1016/j.toxicon.2007.06.022 PMID: 17706737

30. Kaspari M, Weiser MD. Ant activity along moisture gradients in a Neotropical forest. Biotropica. 2000; 32(4):703-11.

31. Levings SC, Windsor DM. Litter moisture content as a determinant of litter arthropod distribution and abundance during the dry season on Barro Colorado Island, Panama. Biotropica. 1984:125-31.

32. Donoso DA, Johnston MK, Kaspari M. Trees as templates for tropical litter arthropod diversity. Oecologia. 2010; 164(1):201-11. https://doi.org/10.1007/s00442-010-1607-3 PMID: 20349247 
33. Donoso DA. Tropical ant communities are in long-term equilibrium. Ecological Indicators. 2017; 83:515-23.

34. Hahn DA, Wheeler DE. Seasonal foraging activity and bait preferences of ants on Barro Colorado Island, Panama. Biotropica. 2002; 34(3):348-56.

35. Folmer O, Black M, Hoeh W, Lutz R, Vrijenhoek R. DNA primers for amplification of mitochondrial cytochrome c oxidase subunit I from diverse metazoan invertebrates. Molecular Marine Biology and Biotechnology. 1994; 3(5):294-9. PMID: 7881515

36. Hebert PD, Ratnasingham S, de Waard JR. Barcoding animal life: cytochrome c oxidase subunit 1 divergences among closely related species. Proceedings of the Royal Society of London B: Biological Sciences. 2003; 270(Suppl 1):S96-S9.

37. Stein SE. An integrated method for spectrum extraction and compound identification from gas chromatography/mass spectrometry data. Journal of the American Society for Mass Spectrometry. 1999; 10 (8):770-81.

38. Daly JW, Garraffo HM, Spande TF. Alkaloids from amphibian skins: Pergamon Press: Amsterdam; 1999.

39. Clark VC, Rakotomalala V, Ramilijaona O, Abrell L, Fisher BL. Individual variation in alkaloid content of poison frogs of Madagascar (Mantella; Mantellidae). Journal of Chemical Ecology. 2006; 32(10):221933. https://doi.org/10.1007/s10886-006-9144-6 PMID: 17013661

40. Born M, Bongers F, Poelman EH, Sterck FJ. Dry-season retreat and dietary shift of the dart-poison frog Dendrobates tinctorius (Anura: Dendrobatidae). Phyllomedusa: Journal of Herpetology. 2010; 9(1):3752.

41. Daly JW, Andriamaharavo NR, Andriantsiferana M, Myers CW. Madagascan poison frogs (Mantella) and their skin alkaloids. American Museum Novitates. 1996; 3177:1-34.

42. Daly J, Wilham J, Spande T, Garraffo H, Gil R, Silva G, et al. Alkaloids in bufonid toads (Melanophryniscus): temporal and geographic determinants for two Argentinian species. Journal of Chemical Ecology. 2007; 33(4):871-87. https://doi.org/10.1007/s10886-007-9261-x PMID: 17333373

43. Daly JW, Myers CW, Warnick JE, Albuquerque EX. Levels of batrachotoxin and lack of sensitivity to its action in poison-dart frogs (Phyllobates). Science. 1980; 208(4450):1383-5. PMID: 6246586

44. Saporito RA, Garraffo HM, Donnelly MA, Edwards AL, Longino JT, Daly JW. Formicine ants: an arthropod source for the pumiliotoxin alkaloids of dendrobatid poison frogs. Proceedings of the National Academy of Sciences of the United States of America. 2004; 101(21):8045-50. https://doi.org/10.1073/pnas. 0402365101 PMID: 15128938

45. Braekman JC, Daloze D. Defensive alkaloids from ants. Journal of the Brazilian Chemical Society. 1996; 7:251-6.

46. Saporito RA, Donnelly MA, Norton RA, Garraffo HM, Spande TF, Daly JW. Oribatid mites as a major dietary source for alkaloids in poison frogs. Proceedings of the National Academy of Sciences. 2007; 104(21):8885-90.

47. Saporito RA, Norton RA, Andriamaharavo NR, Garraffo HM, Spande TF. Alkaloids in the mite Scheloribates laevigatus: further alkaloids common to oribatid mites and poison frogs. Journal of Chemical Ecology. 2011; 37(2):213-8. https://doi.org/10.1007/s10886-011-9914-7 PMID: 21318398

48. Takada W, Sakata T, Shimano S, Enami Y, Mori N, Nishida R, et al. Scheloribatid mites as the source of pumiliotoxins in dendrobatid frogs. Journal of Chemical Ecology. 2005; 31(10):2403-15. https://doi. org/10.1007/s10886-005-7109-9 PMID: 16195851 